\title{
Genrikh Markovich Tseitlin (On His 80th Birthday)
}

DOI: $10.1134 / \mathrm{S} 1560090411120062$

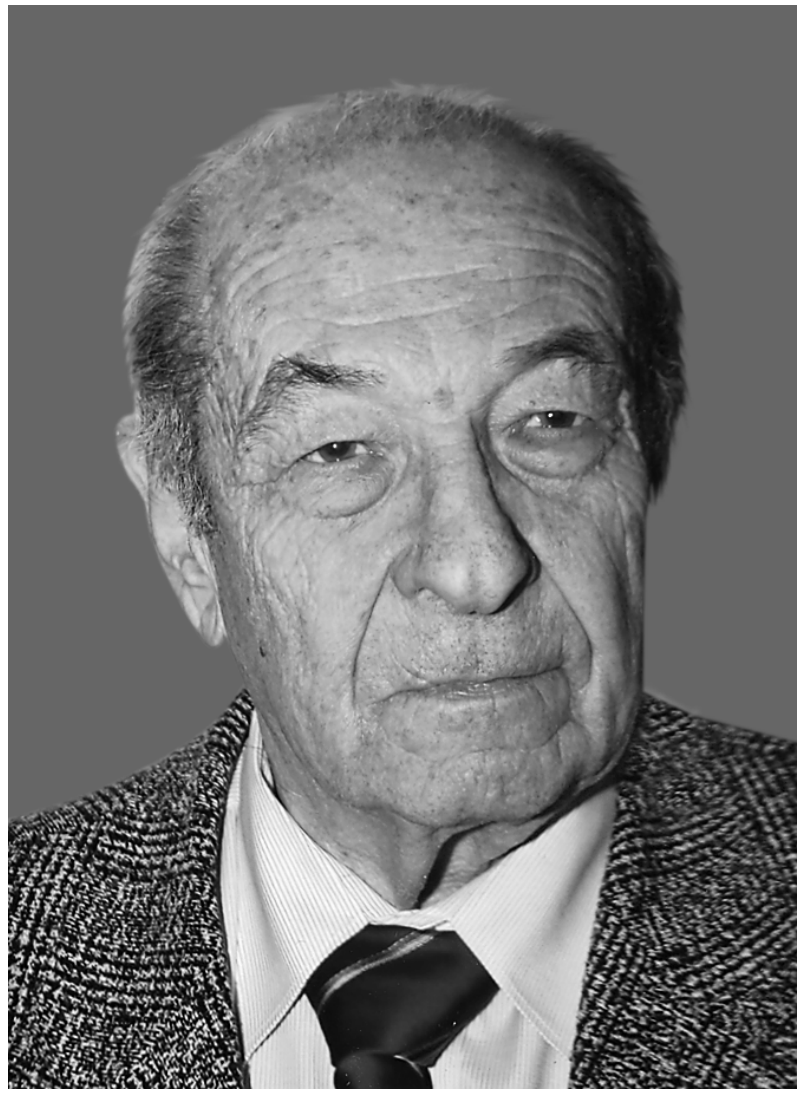

In June 2011, we celebrated the 80th birthday of professor Genrikh Markovich Tseitlin, a famous chemist and a member of the editorial board of Polymer Science.

Tseitlin graduated with honors from the Mendeleev Institute of Chemical Technology (now the Mendeleev University of Chemical Technology); then, in 1953 he was assigned to a job at the Karbolit Chemical Plant in Orekhovo-Zuevo, where he worked until 1956. The same year, Tseitlin entered postgraduate studies at the Department of Plastics, Mendeleev Institute of Chemical Technology, and all his further life was devoted to this institution. In 1957, Tseitlin successfully defended his candidate's dissertation; in 1967, he became a Doctor of Sciences.

Tseitlin's research interests are focused on the field of polycondensation processes. When he was a student, Tseitlin published his first paper, which was devoted to thermal decomposition of hexamethylenetetramine. For a long time, he conducted research in the field of chemistry and technology of heterocy- clochain polymers. The fundamental studies in this field helped develop the technology of polybenzoxazole production, which was taken as a basis for the world's first production of this compound. Polybenzoxazole is used to produce fibers and plastics that are notable for their high thermal and chemical stability. A large cycle of Tseitlin's studies was devoted to epoxide oligomers and their synthesis, hardening, and modification. On the basis of this research, the production of hardening agents (Pilot Plant of the Research Institute of Chemical Current Sources; Electroisolit, Khot'kovo; Research Institute of Plastics) was established; the epoxide production unit in Slavgorod was designed, constructed, and put into operation.

Tseitlin performed a number of applied studies in the field of polyethers. These studies provided the basis for the production of alkyd oligomers with a high solid residue at the St. Petersburg Paint and Varnish Plant and for industrial production of alkyd oligomers based on secondary poly(ethylene terephthalate).

Tseitlin synthesized high-molecular-mass polymers by the reaction between bisphenol diglycidyl esters and amines; these polymers are notable for their improved properties. In addition, interesting data was obtained during investigation of the enzymatic processes of phenol polymerization.

Tseitlin's works have been repeatedly awarded with gold medals at various exhibitions, including foreign ones (Belgium).

Tseitlin was awarded the titles Honored Chemist of the Russian Federation and Honorary Professor of the Mendeleev University of Chemical Technology. He is a member of the Council for Macromolecular Compounds of the Russian Academy of Sciences and a member of the editorial boards of the journals Polymer Science; Klei, kompaundy i germetiki (Glues, Compounds, and Sealants); and Lakokrasochnyie materialy $i$ ikh primenenie (Paints and Varnishes and Their Application). Tseitlin is general director of the journal Khimicheskaya promyshlennost' segodnya (Chemical Industry Today). For 16 years, Tseitlin was the executive in charge for the program of collaboration between polymer scientists from Japan, China, South Korea, and Russia.

Among Tseitlin's pupils, there are 2 doctors of sciences and more than 40 candidates of sciences.

The editorial board of Polymer Science congratulates Genrikh Markovich on his jubilee and wishes him good health and many more years of fruitful creative life. 